\title{
Simulasi Uji Baru Unik Seragam dan Stabil (BUSS) Pisang (Musa spp.) di Kebun Percobaan Pasir Kuda, Bogor
}

\author{
Simulation of Novelty, Distinctness, Uniformity, and Stability (DUS) Test for Banana(Musa spp.) at \\ Experimental field Pasir Kuda, Bogor
}

\author{
Alifiya Herwitarahman, Sobir* \\ Departemen Agronomi dan Hortikultura, Fakultas Pertanian, Institut Pertanian Bogor \\ (Bogor Agricultural University), Jl. Meranti, Kampus IPB Darmaga, Bogor 16680, Indonesia \\ Telp.\&Faks. 62-251-8629353 e-mail agronipb@indo.net.id \\ *email penulis untuk korespondensi: sobir@ipb.ac.id
}

Disetujui 24 Desember 2013/ Published online 13 Februari 2014

\begin{abstract}
The experiment wasconducted toelucidate the characters of distinctness, uniformity and stability (nDUS) test for seven varieties of bananas and plantains that was ambon hijau (AHM), cavendish (CVS), kepok kuning (KKU), kepok unti sayang (KUS), pisang ungu (PUG), pisang lampung (PLP), and pisang mas kirana $(P M K)$ that for simulating the nDUS test important for the plant variety protection right application. The experiment held at experimental field Pasir Kuda, Bogor. Data has been processed with model randomized completely design. The accession conducted in every part of plant, with the sub accession at pseudoterm stem, plant, leaf blade, peduncle, bunch, male inflorescence, rachis, and fruit that used test guidlines TG UPOV 123. The results showed that 50 different characters found from 52 characters in TG $U P O V$ between candidate varieties and refernce variety. The difference could be expresed that the candidate varieties had distinctness character. The uniformity and stability was categorizedwhenthe candidate varieties have not off type character and the source for propagation was from vegetative. The distinctness or the differences used for getting the example varieties. The example varieties that used to make the next test guidlines.
\end{abstract}

Keywords: banana, example, unique, verification

\section{ABSTRAK}

Penelitian ini bertujuan untuk mengidentifikasi sifat unik, seragam dan stabil (BUSS) pada tujuh varietas pisang yaitu ambon hijau (AHM), cavendish (CVS), kepok kuning (KKU), kepok unti sayang (KUS), pisang ungu (PUG), pisang lampung (PLP), dan pisang mas kirana (PMK) sebagai simulasi uji BUSS untuk permohonan hak Perlindungan Varietas Tanaman. Penelitian dilaksanakan di kebun percobaan Pasir Kuda, Bogor. Pengolahan data dilaksanakan dengan menggunakan Rancangan Acak Lengkap. Aksesi dilaksankan pada seluruh bagian tanaman yang dibagi dengan beberapa bagian pengamatan yaitu bagian batang, tanaman, daun, peduncle, tandan, rachis, jantung dan buah menggunakan panduan pengamatan TG UPOV 123. Simulasi ini menghasilkan 50 karakter beda dari 52 karakter pada TG UPOV di antara varietas yang diuji dengan pembanding. Perbedaan tersebut menyatakan bahwa pisang yang diuji memiliki kategori unik.Keseragaman dan kestabilan dilihat dari tidak adanya off type pada varietas pisang yang diuji dan sumber bahan tanam yang diperbanyak secara vegetatif.Perbedaan karakter yang didapat digunakan untuk mendapatkan varietas contoh.Varietas contoh ini berperan untuk pembuatan pedoman pelaksanaan uji selanjutnya.

Kata kunci: contoh, khas, pisang, verifikasi. 


\section{PENDAHULUAN}

Pisang adalah salah satu komoditas buahbuahan unggulan Indonesia. Tahun 2011 luas panen dan produksi pisang sebesar 104156 ha, dengan produksi mencapai 117595 ton (BPS 2011) dan nilai ekonomi sebesar Rp 6.5 triliun. Produksi pisang dan luas panen yang besar merupakan ciri bahwa Indonesia adalah pusat penyebaran pisang. Indonesia merupakan salah satu pusat penyebaran pisang di Asia Tenggara hal ini menyebabkan banyaknya spesies pisang yang terdomestikasi. Tingginya keragaman pisang yaitu lebih dari 200 jenis pisang yang terdapat di Indonesia baik pisang segar, olahan, dan pisang liar. Tingginya keragaman ini menyebabkan masih ada sekitar 100 jenis pisang yang belum dapat teridentifikasi, sehingga masih sulit dalam pelaksanaan pemeliharaan dan klasifikasi plasma nutfah pisang (Megia et al. 2001; Lengkong 2008). Keragaman pisang ini juga belum seluruhnya dapat teridentifikasi jenis pisang maupun karakterkarakter yang membedakannya antara kultivar satu dengan lainya sehingga pengajuan kultivarkultivar pisang baru yang terdapat di Indonesia masih sedikit dilaksanakan.

Indonesia merupakan salah satu negara yang bergabung dengan WTO (World Trade Organisation). Perlindungan varietas sangat menjadi perhatian bagi negara-negara yang tergabung dalam WTO. Perlindungan varietas ini menjadi penting sebab adanya perjanjian TRIPS (Trade-Relatived Aspects of Intellectual Property Rights). Perjanjian ini akan menguntungkan bagi pemulia sebab mereka akan mendapatkan insentif dari kegiatan ini dan memacu keinginan mereka untuk menghasilkan varietas baru (Singh 2007). Pisang merupakan salah satu komoditas hortikultura yang paling banyak diperdagangkan di dunia. Pisang merupakan salah satu komoditas ekspor Indonesia sehingga perlu mendapat perhatian khusus dan mendapatkan perlindungan akibat adanya kegiatan ekspor. Perlindungan varietas ini dapat dilaksanakan dengan melakukan pengujian Baru, Unik, Seragam, dan Stabil (BUSS).

Pengujian BUSS ini bertujuan untuk mengidentifikasi kebaruan, keunikan, keseragaman, dan kestabilan suatu varietas yang diuji dibandingkan dengan varietas referensi. Pengujian ini membutuhkan sebuah deskriptor sebagai pedoman pelaksanaan uji. Pedoman pelaksanaan uji (PPU) yang ada umumnya merupakan deskriptor yang dibuat diluar negeri yang kondisi klimatologi tidak sama seperti
Indonesia. Varietas contoh yang ada dalam deskriptor seperti TG UPOV masih banyak yang belum dikenal, sehingga perlu dicari lagi varietas contoh yang umum ditemui di Indonesia. Berdasarkan hal tersebut perlu dilakukan sebuah pengujian juga pada deskriptor apakah dapat digunakan di Indonesia atau tidak untuk karakterkarakter pada deskriptor. Varietas contoh juga dapat dicari dengan kegiatan pengujian deskriptor dengan melakukan simulasi uji BUSS.

Penelitian ini bertujuan untuk mengetahui perbedaan karakter antara tujuh kultivar yang di uji sehingga dapat dijadikan varietas contoh atau referensi pada pengujian selanjutnya.

\section{BAHAN DAN METODE}

Penelitian dilaksanakan di Kebun Percobaan Pasir Kuda, Bogor, Provinsi Jawa Barat.Penelitian dilaksanakan dari Bulan Oktober 2012 sampai dengan Mei 2013. Bahan tanam yang di amati adalah tujuh jenis kultivar pisang yang terdiri atas pisang kepok unti sayang (KUS), kepok kuning (KKU), pisang lampung (PLP), pisang mas kirana (PMK), ambon hijau (AHM) sebagai varietas pembanding, cavendis (CVS), dan pisang ungu (PUG). Alat-alat yang digunakan untuk mendukung penelitian ini adalah kain berwarna abu-abu, penggaris, color chart , meteran, kamera, timbangan, refractometer, penetrometer, pisau, egrek, dan penggaris.

Pengolahan lahan dilaksanakan oleh petugas kebun mulai bulan Januari untuk penggemburan lahan sehingga lahan siap ditanami.Lubang tanam dibuat denganukuran lubang yang digunakan adalah $50 \times 50 \times 50 \mathrm{~cm}$ untuk tanah-tanah gembur. Jarak tanam $3 \times 3 \mathrm{~m}$. Lubang tanam yang telah selesai dibuat kemudian dilakukan penanaman dilubang tersebut, penanaman dilakukan pada tangal 17 Maret 2012 dengan ukuran bibit antara $30 \mathrm{~cm}-100 \mathrm{~cm}$ yang berasal dari anakan. Sebelum penanaman lubang diberi pupuk organik seperti pupuk kandang/kompos sebanyak $15-20$ kg.Pemupukan organik sangat berpengaruh terhadap kualitas rasa buah.Pemupukan anorganik dilaksanakan sebanyak 4 kali pada awal penanaman, 17 Agustus 2012, 17 November 2012, dan 17 Februari 2013.

Pengamatan dilaksankan berdasarkan panduan dari UPOV (Union for the Protection of New Varieties of Plants).Karakter-karakter yang diamati terbagi atas pengamatan dengan karakter kuantitatif, pseudokualitatif dan kualitatif.Karakter kuantitatif merupakan karakter yang memiliki arah yang jelas atau dapat terukur.Karakter 
pseudokualitatif merupakan karakter yang dapat terukur tetapi terdapat dua arah dalam pengukurannya, karakter ini umumnya adalah karakter warna.Karakter kualitatif merupakan karakter yang tampak pada bahan yang diamati, dinyatakan dengan ada atau tidaknya karakter tersebut pada bahan yang diamati. Total karakter yang diamati adalah sebanyak 52 karakter yang terbagi dalam bagian vegetatif dan generatif.

Bagian vegetatif yang diamati meliputi karakter kuantitatif, pseudokualitatif, dan kualitatif.Pengamatan karakter vegetatif yang diamati meliputi pengamatan pada ploidi pisang, jumlah anakan batang semu pisang, pola pertumbuhan tanaman, dan daun.Pengamatang pada batang semu adalah tinggi, diameter, tumpang tindihnya selebung daun, warna batang semu, ada tidaknya antosianin, warna sisi dalam dari selubung, dan tapering.Pola pertumbuhan tanaman meliputi pola pertumbuhan dan kepadatan mahkota.Pada petiole yaitu pola dari sayap pada dasar dan panjang petiole.Helai daun yaitu warna dari tulang daun pada sisi bawah, bentuk dasar, panjang, lebar, rasio panjang dan lebar daun dan kilau pada sisi atas. Beberapa karakter kuantitatif diamati ketika sudah masuk masa generatif karena pada saat itu pertumbuhan optimum.

Pengamatan generatif dilaksanakan ketika buah mulai berjantung hingga panen. Pengamatan ini terdiri atas pengamatan peduncle, tandan, rachis, jantung, dan buah. Pengamatan pada peduncleini meliputi panjang, diameter, bentuk, dan bulu halus. Panjang tandan, diameter tandan, bentuk, pola terhadap buah, kepadatan dan jumlah sisir pada tadan. Pengamatan rachis meliputi pola terhadap jantung pisang, adanya braktea, adanya bunga hermaprodrit.Pada buah yang diamati apakah bentuk lenkungan pisang, panjang, lebar pisang, panjang pedikel, bentuk dari apex, ketebalan kulit, warna kulit buahsebelum dan sesudah masak, warna daging buah, dan kelembutan daging buah.Organ jantan yaitu jantung pisang yang diamati adalah ada tidaknya, bentuk, terbukanya braktea, dan pengamatan braktea meliputi warna disisi dalam dan bentuk dari sudutnya.Hasil yang telah didapat kemudian dimasukkan kedalam tabel pengamatan yang ada. Analisis data menggunakan RAL (Rancangan Acak Lengkap) dan uji lanjut DMRT.

\section{HASIL DAN PEMBAHASAN}

\section{Simulasi Uji BUSS}

Uji baru, Unik, Seragam dan Stabil (BUSS) merupakan salah satu cara pengujian untuk melindungi tanaman yang akan di lepas. Pengujian ini didasarkan pada Pasal 1 Ayat 3 Undang-undang Nomor 29 Tahun 2000 tentang perlindungan varietas tanaman (PVT) yang menjelaskan bahwa varietas tanaman yang selanjutnya disebut varietas, adalah sekelompok tanaman dari suatu jenis atau spesies yang ditandai oleh bentuk tanaman, pertumbuhan tanaman, daun, bunga, buah, biji, dan ekspresi karakteristik genotipe atau kombinasi genotipe yang dapat membedakan dari jenis atau spesies yang sama oleh sekurang-kurangnya satu sifat yang menentukan dan apabila diperbanyak tidak mengalami perubahan (Deptan 2006). Uji BUSS salah satunya dilaksanakan atas dampak perdagangan bebas khususnya untuk negara berkembang, bahwa tanaman-tanaman yang diperdagangkan sebaiknya memiliki sebuah perlindungan atau lebih dikenal dengan istilah perjanjian TRIPS (Trade-Relatived Aspects of Intellectual Property Rights). Uji BUSS juga dilaksanakan guna melindungi pemulia tanaman yang ingin melepaskan varietas dan menjadikan sebuah insentif bagi mereka,semakin banyak orang yang berkecimpung dibidang penelitian ini dan kemudian banyak dihasilkan varietas baru. Varietas baru yang akan dilindungi harus memilki persyaratan kebaruan, unik, seragam dan stabil untik varietas yang diuji (Lalitha 2004; Gazaro 2006; Singh 2007; Santos et al. 2012).

Parameter pengamatan yang digunakan dibagi dalam beberapa sub bab yaitu pengamatan karakter batang semu, tanaman, daun, peduncle dan tandan, jantung atau organ jantan dan buah. Hasil pengamatan dinyatakan pada beberapa tabel berikut dibawah ini.

\section{Karakter Batang}

Berdasarkan data Tabel 1 diatas pisang ungu memiliki kekhasan yang paling menonjol dalam hal warna batang, antosianin dan warna batang semu pada nya yaitu warna ungu. Perbedaan yang khas antara pisang AHM dengan CVS adalah warna batang pada pisang ambon hijau berwarna merah kehijauan sedangkan pada pisang CVS adalah hijau kekuningan. Pada pisang KKU dengan KUS perbedaan terlihat dari warna batangnya hijau kekuningan pada KKU, dan hijau 
muda pada KUS.Warna basal batang juga memiliki perbedaan yaitu warna KKU kuning kehijauan dan KUS berwarna hijau. Pada PLP dengan PMK ciri khas yang membedakan adalah warna batang semunya yang membedakan, serta kandungan antosianin seperti yang tertera pada Tabel 1. Hasil kuantitatif tanaman diatas menyatakan bahwa tinggi tanaman yang paling tinggi adalah pisang kepok kuning, tinggi tanaman yang memiliki cukup tinggi adalah kepok unti sayang, kemudian adalah PUG dan CVS yang memiliki tinggi yang tidak berbeda nyata dan yang memiliki tinggi yang pendek adalah PLP, PMK, dan AHM. Diameter tanaman yang paling besar adalah pisang KKU, KUS dan PUG, kemudian yang sedang adalah CVS dan yang diameter paling kecil adalah PMK, PLP dan AHM. Karakter ukuran baik tinggi maupun diameter berkaitan erat dengan jumlah ploidi, hal ini seperti yang disampaikan oleh Megia (2005), yang menyatakan bahwa penampakan batang dan buah akan lebih besar pada pisang dengan jumlah ploidi yang triploid dibandingkan dengan yang diploid.

Tabel 1. Karakter bagian batang semu

\begin{tabular}{|c|c|c|c|c|c|c|c|c|}
\hline No & Karakter & AHM & CVS & KKU & KUS & PUG & PLP & PMK \\
\hline $\begin{array}{c}1 . \\
(*) \\
(+) \mathrm{QL}\end{array}$ & Ploidy & Triploid (3) & Triploid (3) & Triploid (3) & Triploid (3) & Triploid (3) & Diploid (1) & Diploid (1) \\
\hline $\begin{array}{c}2 . \\
(+) \text { QN }\end{array}$ & $\begin{array}{l}\text { Rhizome: jumlah } \\
\text { sucker didalam } \\
\text { tanah }\end{array}$ & Sedang (5) & Sedang (5) & Sedang (5) & Sedang (5) & Sedikit (1) & Banyak (7) & Banyak (7) \\
\hline $\begin{array}{c}3 . \\
(*) \\
(+) Q N \\
\end{array}$ & Tinggi tanaman & $\begin{array}{l}\text { Pendek (3) } \\
183.42 d\end{array}$ & $\begin{array}{l}\text { Medium (5) } \\
265.50 \mathrm{c}\end{array}$ & $\begin{array}{l}\text { Sangat tinggi (9) } \\
423 a\end{array}$ & $\begin{array}{l}\text { Tinggi (7) } \\
371.25 \mathrm{~b}\end{array}$ & $\begin{array}{l}\text { Medium (5) } \\
235 c\end{array}$ & $\begin{array}{l}\text { Pendek (3) } \\
144.86 \mathrm{~d}\end{array}$ & $\begin{array}{l}\text { Pendek (3) } \\
180.30 d\end{array}$ \\
\hline $\begin{array}{c}4 . \\
(*) \\
(+) Q N\end{array}$ & $\begin{array}{l}\text { Batangsemu: } \\
\text { Diameter } \\
\text { tanaman }\end{array}$ & $\begin{array}{l}\text { Kecil (1) } \\
14.257 \mathrm{c}\end{array}$ & $\begin{array}{l}\text { Sedang (2) } \\
19.745 b\end{array}$ & $\begin{array}{l}\text { Luas (3) } \\
29.936 a\end{array}$ & $\begin{array}{l}\text { Luas (3) } \\
28.424 a\end{array}$ & $\begin{array}{l}\text { Luas (3) } \\
28.662 \mathrm{a}\end{array}$ & $\begin{array}{l}\text { Kecil (1) } \\
10.628 \mathrm{c}\end{array}$ & $\begin{array}{l}\text { Kecil } \\
(1) \\
10.936 \mathrm{c}\end{array}$ \\
\hline $\begin{array}{l}5 . \\
(+)\end{array}$ & $\begin{array}{l}\text { Batangsemu: } \\
\text { tumpangtindih } \\
\text { selubung daun }\end{array}$ & Sedang (2) & Sedang (2) & Sedang (2) & Sedang (2) & Kuat (3) & Lemah (1) & Lemah (1) \\
\hline $\begin{array}{c}6 . \\
(+) \text { QN }\end{array}$ & $\begin{array}{l}\text { Batangsemu: } \\
\text { meruncing }\end{array}$ & $\operatorname{Lemah}(1)$ & Sedang (2) & Sedang (2) & Sedang (2) & Kuat (3) & Lemah (1) & Lemah (1) \\
\hline $\begin{array}{l}7 . \\
\text { PQ }\end{array}$ & $\begin{array}{l}\text { Batangsemu: } \\
\text { warna }\end{array}$ & $\begin{array}{l}\text { Merah } \\
\text { kehijauan (5) }\end{array}$ & $\begin{array}{l}\text { Hijau } \\
\text { kekuningan } \\
\text { (1) }\end{array}$ & $\begin{array}{l}\text { Hijau } \\
\text { kekuningan (1) }\end{array}$ & $\begin{array}{l}\text { Hijau muda } \\
\text { (2) }\end{array}$ & Ungu (7) & $\begin{array}{l}\text { Merah } \\
\text { kehijauan } \\
\text { (5) }\end{array}$ & $\begin{array}{l}\text { Hijau } \\
\text { kekuningan } \\
\text { (1) }\end{array}$ \\
\hline $\begin{array}{c}8 . \\
(+) \text { QN }\end{array}$ & $\begin{array}{l}\text { Batangsemu: } \\
\text { pewarnaan } \\
\text { antosyanin }\end{array}$ & Kuat (7) & Kuat (7) & Lemah (3) & Lemah (3) & Sangat kuat(9) & Kuat (7) & Medium (5) \\
\hline 9. P & $\begin{array}{l}\text { Batangsemu } \\
\text { :warna dari sisi } \\
\text { dalam dari } \\
\text { selubung basal } \\
\end{array}$ & Hijau (2) & Hijau (2) & $\begin{array}{l}\text { Kuning } \\
\text { kehijauan (1) }\end{array}$ & Hijau (2) & Ungu (4) & Merah (3) & Merah (3) \\
\hline
\end{tabular}

${ }^{a}$ AHM merupakan varietas pembanding. Tanda asterik (*): karakter penting yang pasti harus ada pada pengujian BUSS diseluruh tempat yang bergabung dengan UPOV sebagai harmonisasi pengamatan internasional. Tanda (+): contoh pengamatan ada dalam TG UPOV. QN: kuantitatif karakter. QL: kualitatif karakter. PQ: pseudokualitatif karakter. Nilai tengah yang diikuti oleh huruf yang sama pada baris yang sama menunjukkan tidak berbeda nyata pada hasil yang uji lanjut DMRT dengan taraf 5\%

\section{Karakter Tanaman dan Daun}

Pengamatan karakter pada Tabel 2 ini mendapatkan hasil bahwa tanaman yang diuji memiliki karakter tanaman dengan pola penyebaran menyebar. Pisang CVS jika dibandingkan dengan varietas pembanding yaitu AHM memiliki ciri-ciri yang hampir mirip dari sisi tanaman dan daun, kecuali pada bagian bawah daun dimana bawah daun AHM meruncing sedangkan CVS salah satu ada yang melengkung dan meruncing, petiole/ tangkai daun pada CVS juga lebih panjang dari AHM. Varietas pembanding sendiri lapisan lilin pada daun ada dalam kategori lemah sementara PUG, KKU dan KUS memiliki karakter lapisan lilin yang kuat. Daun varietas pembanding juga tidak memiliki kilap pada permukaan daun, tetapi pisang KKU, KUS, PUG, dan PMK memiliki kilap di permukaan daun. Panjang daun terpanjang adalah 
varietas KKU, KUS, dan PUG, panjang daun yang pendek terdapat pada varietas PMK dan PLP.

Tabel 2. Karakter tanaman dan daun

\begin{tabular}{|c|c|c|c|c|c|c|c|c|}
\hline & Karakter & AHM & CVS & KKU & KUS & PUG & PLP & PMK \\
\hline $\begin{array}{l}10 . \\
(+)\end{array}$ & $\begin{array}{l}\text { Tanaman } \\
\text { kepadatan } \\
\text { mahkota }\end{array}$ & Sedang (5) & Sedang (5) & Lepas (3) & Sedang (5) & Lepas (3) & Lepas (3) & Lepas (3) \\
\hline $\begin{array}{l}11 . \\
(*) \\
(+)\end{array}$ & $\begin{array}{l}\text { Tanaman : pola } \\
\text { pertumbuhan }\end{array}$ & Menyebar (2) & Menyebar (2) & Menyebar (2) & Menyebar (2) & Menyebar (2) & Menyebar (2) & Menyebar (2) \\
\hline $\begin{array}{l}12 . \\
\text { QN } \\
(+)\end{array}$ & $\begin{array}{l}\text { Petiole : pola } \\
\text { dari sayap pada } \\
\text { dasar }\end{array}$ & $\begin{array}{l}\text { Melengkung } \\
\text { ke luar (1) }\end{array}$ & $\begin{array}{l}\text { Melengkung } \\
\text { ke luar (1) }\end{array}$ & $\begin{array}{l}\text { Melengkung } \\
\text { ke dalam (3) }\end{array}$ & $\begin{array}{l}\text { Melengkung } \\
\text { ke dalam (3) }\end{array}$ & $\begin{array}{l}\text { Melengkung } \\
\text { ke luar (1) }\end{array}$ & $\begin{array}{l}\text { Melengkung } \\
\text { ke luar (1) }\end{array}$ & $\begin{array}{l}\text { Melengkung } \\
\text { ke luar (1) }\end{array}$ \\
\hline
\end{tabular}

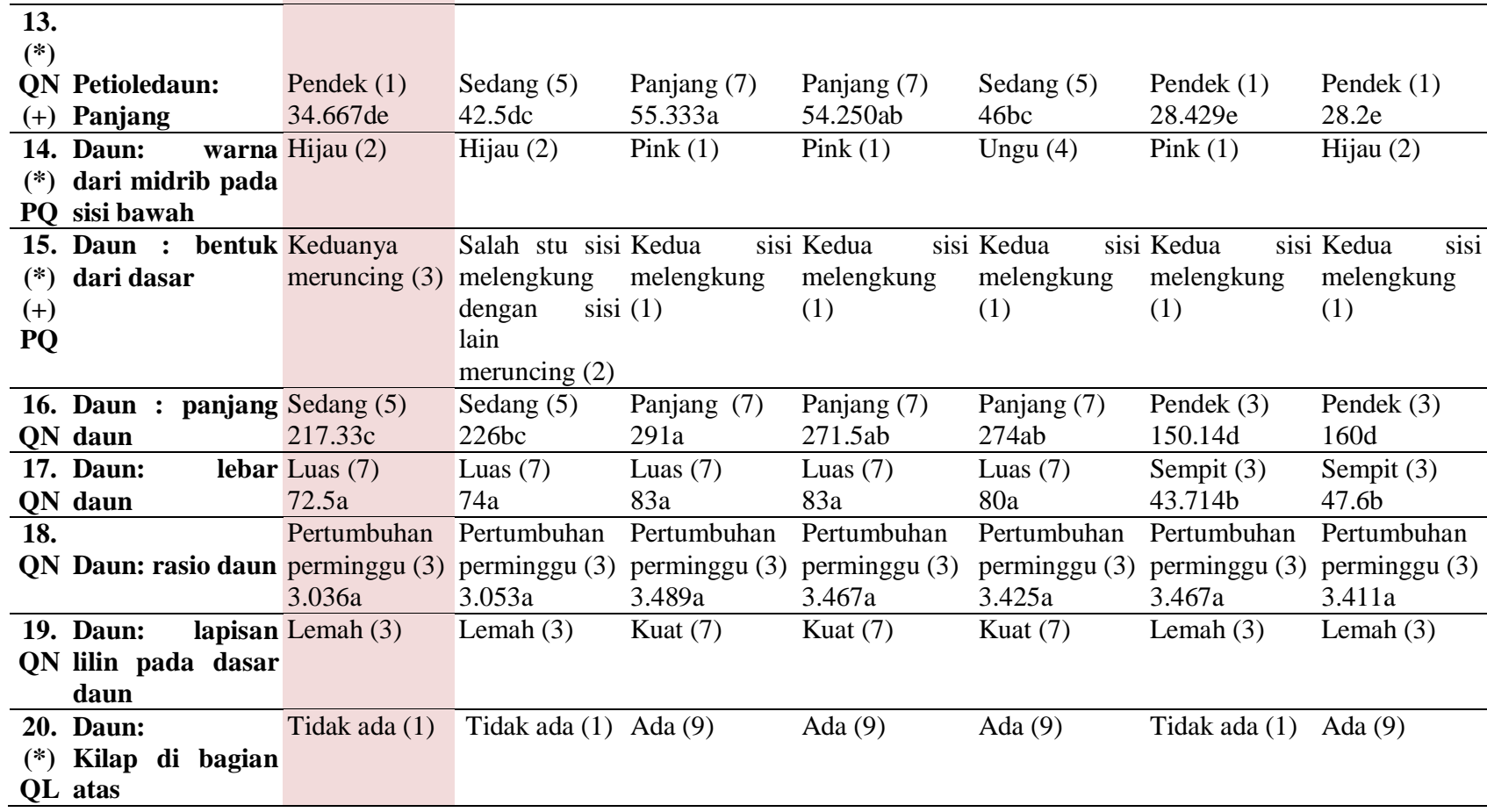

${ }^{\mathrm{a}} \mathrm{AHM}$ merupakan varietas pembanding. Tanda asterik (*): karakter penting yang pasti harus ada pada pengujian BUSS diseluruh tempat yang bergabung dengan UPOV sebagai harmonisasi pengamatan internasional. Tanda (+): contoh pengamatan ada dalam TG UPOV. QN: kuantitatif karakter. QL: kualitatif karakter. PQ: pseudokualitatif karakter. Nilai tengah yang diikuti oleh huruf yang sama pada baris yang sama menunjukkan tidak berbeda nyata pada hasil yang uji lanjut DMRT dengan taraf 5\%

\section{Karakter Peduncle, Rachis dan Tandan}

Berdasarkan Tabel 3, seluruh varietas yang diuji rata-rata memiliki bulu halus pada peduncel/ tangkai tandan kecuali tanaman KKU dan KUS. Varietas pembanding juga memilki kesamaan dengan CVS kembali dalam hal kelengkungan peduncle yang kuat sementara yang lain memiliki kelengkungan yang lemah. Perbedaan yang khas lagi adalah bentuk tandan yaitu pola terhadap buah dimana CVS memiliki kesamaan dengan varietas pembanding AHM, sementara yang lain KKU dan KUS memiliki pola moderat sedikit keatas, sedangkan PUG, PLP, dan PMK memiliki pola horizontal- sedikit naik. Bentuk tandan KUS, KKU, dan CVS memiliki kesamaan dengan varietas pembanding yaitu cylindrical sementara PLP, PMK, dan PUG memiliki bentuk irregular. Pada bagian rachis semua tanaman yang di uji tidak memiliki braktea yang menutupi rachis. Keberadaan bunga hemaprodit rata-rata semua varietas memiliki bunga hemprodit kecuali KUS. Berdasarkan tabel diatas urutan karakter tandan yang terpanjang adalah KKU, KUS, AHM, CVS, PUG, PLP dan PMK. Lebar terlebar urutanya adalah KUS, PUG, AHM, CVS, KKU, PLP, dan PMK. Berdasarkan penelitian Wirnas et al. (2005) karakter kuantitatif tandan ini dapat dipengaruhi oleh umur berbunga dan panen semakin lama semakin besar, karakter tinggi tanaman, lebar tanaman, dan daun. 
Tabel 3. Karakter peduncle, rachis dan tandan

\begin{tabular}{|c|c|c|c|c|c|c|c|c|}
\hline No & Karakter & AHM & CVS & KKU & KUS & PUG & PLP & PMK \\
\hline $\begin{array}{l}21 . \\
(+) \\
\text { QN }\end{array}$ & Panjang peduncle & $\begin{array}{l}\text { Sedang (5) } \\
\text { 42ab }\end{array}$ & $\begin{array}{l}\text { Sedang (5) } \\
49 \mathrm{ab}\end{array}$ & $\begin{array}{l}\text { Panjang (7) } \\
50.5 \mathrm{a}\end{array}$ & $\begin{array}{l}\text { Panjang (7) } \\
53 \mathrm{a}\end{array}$ & $\begin{array}{l}\text { Sedang (5) } \\
50 \mathrm{ab}\end{array}$ & $\begin{array}{l}\text { Pendek (3) } \\
31.57 \mathrm{bc}\end{array}$ & $\begin{array}{l}\text { Pendek (3) } \\
25 \mathrm{bc}\end{array}$ \\
\hline $\begin{array}{l}22 . \\
(+) \\
\text { QN }\end{array}$ & Lebar peduncle & $\begin{array}{l}\text { Kecil (3) } \\
4.396 \mathrm{bc}\end{array}$ & $\begin{array}{l}\text { Kecil (3) } \\
4.185 \mathrm{c}\end{array}$ & $\begin{array}{l}\text { Besar (7) } \\
7.006 \mathrm{a}\end{array}$ & $\begin{array}{l}\text { Sedang (5) } \\
6.051 \mathrm{ab}\end{array}$ & $\begin{array}{l}\text { Sedang (5) } \\
6.051 \mathrm{ab}\end{array}$ & $\begin{array}{l}\text { Kecil (3) } \\
4.39 b c\end{array}$ & $\begin{array}{l}\text { Kecil (3) } \\
3.822 \mathrm{c}\end{array}$ \\
\hline $\begin{array}{l}23 . \\
(*)\end{array}$ & $\begin{array}{l}\text { Peduncle : } \\
\text { rambut halus }\end{array}$ & Ada (1) & Ada (1) & Tidak ada (9) & $\begin{array}{l}\text { Tidak } \\
\text { adaada (9) }\end{array}$ & Ada (1) & Ada (1) & Ada (1) \\
\hline $\begin{array}{l}24 . \\
(+) \\
\text { QN } \\
\end{array}$ & $\begin{array}{l}\text { Peduncle: } \\
\text { kelengkungan }\end{array}$ & Kuat (7) & Kuat (7) & Lemah (3) & Lemah (3) & Lemah (3) & Lemah (3) & Lemah (3) \\
\hline $\begin{array}{l}25 . \\
(*) \\
(+) \\
\text { QN } \\
\end{array}$ & Panjang tandan & $\begin{array}{l}\text { Panjang (7) } \\
64 a\end{array}$ & $\begin{array}{l}\text { Sedang (5) } \\
53.5 \mathrm{ab}\end{array}$ & $\begin{array}{l}\text { Panjang (7) } \\
66.5 \mathrm{a}\end{array}$ & $\begin{array}{l}\text { Panjang (7) } \\
64 \mathrm{a}\end{array}$ & $\begin{array}{l}\text { Sedang (5) } \\
52 \mathrm{ab}\end{array}$ & $\begin{array}{l}\text { Pendek (3) } \\
36.14 \mathrm{bc}\end{array}$ & $\begin{array}{l}\text { Pendek (3) } \\
26 c\end{array}$ \\
\hline $\begin{array}{l}\mathbf{2 6} \\
(*) \\
(+) \\
\text { QN } \\
\end{array}$ & Lebar tandan & $\begin{array}{l}\text { Sedang (5) } \\
29.936 \mathrm{ab}\end{array}$ & $\begin{array}{l}\text { Sedang (5) } \\
28.572 \mathrm{abc}\end{array}$ & $\begin{array}{l}\text { Sedang (5) } \\
28.342 \mathrm{abc}\end{array}$ & $\begin{array}{l}\text { Luas (7) } \\
31.847 \mathrm{a}\end{array}$ & $\begin{array}{l}\text { Luas (7) } \\
30.573 \mathrm{ab}\end{array}$ & $\begin{array}{l}\text { Sempit (3) } \\
21.929 b c\end{array}$ & $\begin{array}{l}\text { Sempit (3) } \\
20.064 c\end{array}$ \\
\hline $\begin{array}{l}27 . \\
(+) \\
\text { PQ } \\
\end{array}$ & Tandan : bentuk & Cylindrical (1) & Cylindrical (1) & Cylindrical (1) & $\begin{array}{l}\text { Cylindrical } \\
\text { (1) }\end{array}$ & Irregular(2) & $\begin{array}{l}\text { Irregular(2 } \\
)\end{array}$ & Irregular(2) \\
\hline $\begin{array}{l}\mathbf{2 8} \\
(*) \\
(+) \\
\text { QN } \\
\end{array}$ & $\begin{array}{l}\text { Tandan : pola } \\
\text { terhadap buah }\end{array}$ & Sangat naik (3) & Sangat naik(3) & $\begin{array}{l}\text { Moderat ke } \\
\text { atas (2) }\end{array}$ & $\begin{array}{l}\text { Moderat ke } \\
\text { atas (2) }\end{array}$ & $\begin{array}{l}\text { Horizontal - } \\
\text { sedikit naik } \\
\text { (1) }\end{array}$ & $\begin{array}{l}\text { Horizontal- } \\
\text { sedikit naik } \\
\text { (1) }\end{array}$ & $\begin{array}{l}\text { Horizontal - } \\
\text { sedikit naik } \\
\text { (1) }\end{array}$ \\
\hline $\begin{array}{l}29 . \\
\text { QN }\end{array}$ & $\begin{array}{l}\text { Tandan : } \\
\text { kepadatan }\end{array}$ & Padat (7) & Padat (7) & Padat (7) & Padat (7) & Medium (5) & Padat (7) & Padat (7) \\
\hline $\begin{array}{l}\text { 30. } \\
(*) \\
(+) \\
\text { QN } \\
\end{array}$ & Jumlah sisir & $\begin{array}{l}\text { Sedang (5) } \\
5.5 \mathrm{bc}\end{array}$ & $\begin{array}{l}\text { Sedang (5) } \\
8 \mathrm{~b}\end{array}$ & $\begin{array}{l}\text { Banyak (7) } \\
11 \mathrm{a}\end{array}$ & $\begin{array}{l}\text { Banyak (7) } \\
12 \mathrm{a}\end{array}$ & $\begin{array}{l}\text { Sedikit (1) } \\
5 c\end{array}$ & $\begin{array}{l}\text { Sedang (5) } \\
6.857 \mathrm{cb}\end{array}$ & $\begin{array}{l}\text { Sedang (5) } \\
5.5 \mathrm{bc}\end{array}$ \\
\hline $\begin{array}{l}31 . \\
(*) \\
(+) \\
\text { PQ }\end{array}$ & $\begin{array}{l}\text { Rachis: pola dari } \\
\text { bunga jantan }\end{array}$ & Vertikal (1) & Vertikal (1) & Vertikal (1) & - & Inclined (2) & Vertikal (1) & $\begin{array}{l}\text { Horizontal } \\
\text { dengan akhir } \\
\text { inklin (4) }\end{array}$ \\
\hline $\begin{array}{l}32 . \\
(+) \\
\text { QN } \\
\end{array}$ & $\begin{array}{l}\text { Rachis: } \\
\text { penampakan } \\
\text { parut }\end{array}$ & Sedang (2) & Lemah (1) & Kuat (3) & - & Lemah (1) & Sedang (2) & Sedang (2) \\
\hline $\begin{array}{l}33 . \\
(*) \\
(+) \\
\text { QN } \\
\end{array}$ & $\begin{array}{l}\text { Rachis: } \\
\text { keberadaan } \\
\text { braktea }\end{array}$ & Tidak ada (1) & Tidak ada (1) & Tidak ada (1) & $\begin{array}{l}\text { Tidak ada } \\
\text { (1) }\end{array}$ & $\begin{array}{l}\text { Tidak ada } \\
\text { (1) }\end{array}$ & $\begin{array}{l}\text { Tidak ada } \\
\text { (1) }\end{array}$ & Tidak ada (1) \\
\hline $\begin{array}{l}34 . \\
\text { QL }\end{array}$ & $\begin{array}{l}\text { Rachis: } \\
\text { keberadaan } \\
\text { bunga } \\
\text { hemaprodit }\end{array}$ & Ada (1) & Ada (1) & Ada (1) & $\begin{array}{l}\text { Tidak ada } \\
\text { (9) }\end{array}$ & Ada (1) & Ada (1) & Ada (1) \\
\hline
\end{tabular}

${ }^{\mathrm{a}} \mathrm{AHM}$ merupakan varietas pembanding. Tanda asterik (*): karakter penting yang pasti harus ada pada pengujian BUSS diseluruh tempat yang bergabung dengan UPOV sebagai harmonisasi pengamatan internasional. Tanda (+): contoh pengamatan ada dalam TG UPOV. QN: kuantitatif karakter. QL: kualitatif karakter. PQ: pseudokualitatif karakter. Nilai tengah yang diikuti oleh huruf yang sama pada baris yang sama menunjukkan tidak berbeda nyata pada hasil yang uji lanjut DMRT dengan taraf 5\%

\section{Karakter Jantung}

Jantung pisang merupakan bagian dari bunga pisang yang bersifat steril yang kemudian tidak dapat menjadi buah, sehingga disebut sebagai bunga jantan (Inibap 2001). Bentuk jantung pisang memiliki beberapa varietas dimana bentuk AHM memiliki kemiripan dengan CVS yaitu berbentuk narrow ovate, sedangkan KKU memilki bentuk broad ovate, PLP berbentuk lanceolate dan PMK berbentuk medium ovate. Bentuk ujung braktea AHM dan CVS memilki bentuk yang berbentuk broad acute, KKU obtuse, PLP narrow acute dan PMK right angle. Warna dalam braktea, varietas pembanding orange kemerahan samai PMK, CVS dan KKU berwarna 
merah dan PMK berwrna pink. PUG belum ada data jantung karena buah yang sudah berbuah yang diamti dengan jantung yang sudah hilang.
Sementara KUS merupakan pisang yang tidak memiliki jantung pisang, dengan nama lokal kepok lokal nipah (Suhartanto et al. 2009).

Tabel 4. Karakter jantung

\begin{tabular}{|c|c|c|c|c|c|c|c|}
\hline No & Karakter & AHM & CVS & KKU & $\begin{array}{ll}\text { KUS } & \text { PUG }\end{array}$ & PLP & PMK \\
\hline $\begin{array}{l}48 . \\
(*) \\
(+) \\
\text { QL }\end{array}$ & $\begin{array}{l}\text { Jantung pisang: } \\
\text { keberadaan }\end{array}$ & Ada (1) & Ada (1) & Ada (1) & $\begin{array}{l}\text { Tidak Ada (1) } \\
\text { ada (2) }\end{array}$ & Ada (1) & Ada (1) \\
\hline $\begin{array}{l}49 . \\
(+) \\
\text { QN }\end{array}$ & $\begin{array}{l}\text { Jantung pisang: } \\
\text { bentuk }\end{array}$ & $\begin{array}{l}\text { Narrow ovate } \\
\text { (2) }\end{array}$ & $\begin{array}{l}\text { Narrow ovate } \\
\text { (2) }\end{array}$ & Broad ovate(4) & - & $\begin{array}{l}\text { Lanceolate } \\
\text { (1) }\end{array}$ & $\begin{array}{l}\text { Medium } \\
\text { ovate(3) }\end{array}$ \\
\hline $\begin{array}{l}50 . \\
(+) \\
\text { QN }\end{array}$ & $\begin{array}{l}\text { Jantung pisang: } \\
\text { pembukaan } \\
\text { braktea }\end{array}$ & $\begin{array}{l}\text { Tertutup atau } \\
\text { sedikit } \\
\text { membuka (1) }\end{array}$ & $\begin{array}{l}\text { Tertutup atau } \\
\text { sedikit } \\
\text { membuka (1) }\end{array}$ & $\begin{array}{l}\text { Sangat terbuka } \\
\text { (3) }\end{array}$ & - & $\begin{array}{l}\text { Tertutup atau } \\
\text { sedikit } \\
\text { membuka (1) }\end{array}$ & $\begin{array}{c}\text { Terbuka } \\
\text { sedang (2) }\end{array}$ \\
\hline $\begin{array}{l}51 . \\
\text { PQ }\end{array}$ & $\begin{array}{l}\text { Braktea: warna } \\
\text { dalam braktea }\end{array}$ & $\begin{array}{l}\text { Orange } \\
\text { kemerahan (6) }\end{array}$ & Merah (7) & Merah (7) & - & $\begin{array}{c}\text { Orange } \\
\text { kemerahan (6) }\end{array}$ & Pink (5) \\
\hline $\begin{array}{l}52 . \\
(+) \\
\text { PQ }\end{array}$ & $\begin{array}{l}\text { Braktea: bentuk } \\
\text { ujung }\end{array}$ & Broad acute(2) & Broad acute(2) & Obtuse(4) & - & $\begin{array}{l}\text { Narrow } \\
\text { acute(1) }\end{array}$ & Right angle(3) \\
\hline
\end{tabular}

\section{Karakter buah}

Buah merupakan bagian penting dari pertanaman pisang, karena bagian inilah yang akan dikonsumsi. Karakter pada buah juga dapat menjadi salah satu pembeda yang khas diantara karakter-karakter yang diuji, hasil dapat dilihat pada Tabel 5. Bagian punggung bujur buah menunjukan pisang AHM dan CVS memilki bentuk moderat, KUS dan KKU bentuknya sangat kuat sedang PLP, PMK dan PUG berbentuk lemah. Bentuk kelengkungan buah juga menggambarkan bahwa pisang AHM memiliki kelengkungan dibagian ujung, CVS agak memelngkun, KKU, KUS, PLP, PMK dan PUG memilki bentuk buah yang lurus. Ukuran pisang juga menggambarkan bahwa CVS dan AHM tergolong pisang dengan ukuran panjang, KKU, KUS, dan PUG golongan pisang dengan panjang sedang, dan PLP dan PMK golongan pisang kecil. Adanya beberapa kemiripan antar buah dapat dibedakan juga melalui bagian bawah buah dimana bentuk bawah buah pisang PUG, AHM dan CVS berbentuk truncate, KUS, dan KKU berbentuk pointed, PLP berbentu bottle necked dan PMK berbentuk rounded. Warna buah merupakan salah satu penciri yang dapat dengan mudah untuk membedakan satu sama lain. Warna buah ketika masak untuk pisang AHM dan CVS adalah hijau kekuningan sedangkan, KUS dan KKU memilki warna kuning, serta PLP dan PMK warnanya kuning cerah. PUG memilki ciri khas warna kulit yang paling berbeda yaitu warnanya ungu ketika muda dan masak menjadi merah agak oranye.

Berdasarkan hasil kegiatan pengujian simulasi BUSS pisang dilapang, varietas yang diuji dapat dikategorikan baru apabila pisang ini bahan perbanyakannya atau hasil panennya belum pernah diperdagangkan tidak lebih dari setahun, atau diluar negeri lebih dari empat tahun untuk tanaman semusim dan enam tahun untuk tanaman tahunan (Syukur et al. 2012). Karakter baru tidak diuji secara langsung, tetapi hal ini dapat terlihat dari jenis-jenis pisang yang diamati yang umumnya belum umum dipasaran dan kebanyakan masih dikenal dengan penamaan-penamaan lokal. Karakter pisang yang diuji memiliki perbedaan karakter morfologi dengan pisang yang menjadi pembanding. Karakterisasi berdasarkan penanda morfologi kualitatif merupakan pendekatan yang dapat digunakan untuk mengatasi masalah duplikasi plasma nutfah (Simmonds dan Shepherd 1955). Terdapat 50 karakter yang berbeda dari 52 karakter yang diamati. varietas yang diuji memiliki kekhasannya masing-masing yang menjadi pembeda diantara setiap varietas sehingga varietas yang diuji dapat dinyatakan dengan kategori unik. Pengamatan yang dilakukan pada seluruh karakter yang ada di Kebun Percobaan Pasir Kuda menyatakan keseragaman dimana tidak ada varietas yang off type, yang teramati. Keseragaman yang ada menandakan bahwa pisang-pisang ini dapat dianggap stabil karena sumber pisang ini berasal dari anakan atau perbanyakan secara vegetatif dengan rata-rata indukan yang sama. 
Tabel 5. Karakter buah

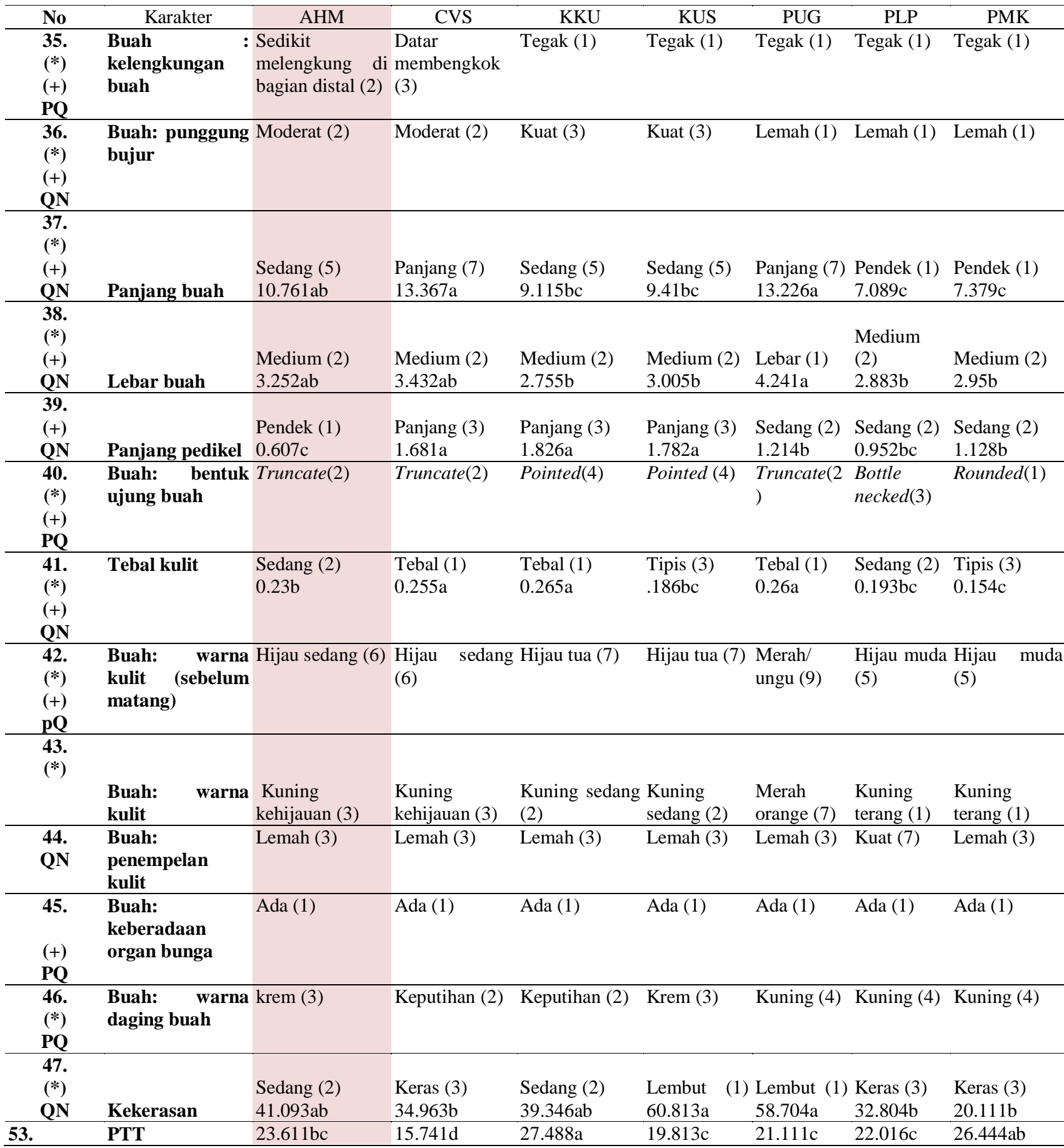

${ }^{a}$ AHM merupakan varietas pembanding. Tanda asterik (*): karakter penting yang pasti harus ada pada pengujian BUSS diseluruh tempat yang bergabung dengan UPOV sebagai harmonisasi pengamatan internasional. Tanda $(+)$ : contoh pengamatan ada dalam TG UPOV. QN: kuantitatif karakter. QL: kualitatif karakter. PQ: pseudokualitatif karakter. Nilai tengah yang diikuti oleh huruf yang sama pada baris yang sama menunjukkan tidak berbeda nyata pada hasil yang uji lanjut DMRT dengan taraf 5\%

Berdasarkan pengamatan yang telah dilaksanakan, seluruh karakter dapat diamati dengan tabel test guidlines ( $\operatorname{tg}$ ) UPOV, tetapi masih perlu ada penambahan karakter sesuai dengan kondisi lingkungan di Indonesia. Hal ini menyatakan bahwa $t g$ UPOV ini dapat diaplikasikan di Indonesia untuk pengamatan uji
BUSS selajutnya. Simulasi uji BUSS ini juga berperan untuk menghasilkan varietas contoh yang dapat dicantumkan pada tg UPOV selanjutnya, sebagai pembanding. Varietas contoh ini ditentukan berdasarkan notasi angka yang diberikan pada Tabel. 


\section{KESIMPULAN}

Simulasi uji BUSS ini telah dapat mengidentifikasi beberapa kekhasan dari beberapa varietas yang diuji jika dibandingkan dengan varietas pembanding.Karakter pisang yang diuji memiliki perbedaan karakter sebanyak 50 perbedaan dari 52 karakter yang diamati dengan varietas pembanding.Adanya perbedaan antara varietas yang diuji sehingga dapat dinyatakan sebagai kategori unik.

Keseragaman dinyatakan dengan tidak adanya off type pada pisang yang diamati. Sumber pisang yang diamati berasal dari perbanyakan vegetatif dan pisang dinyatakan telah seragam sehingga dapat dikategorikan pisang yang diuji stabil.Pengamatan yang dilakukan menyatakan kestabilan dimana tidak ada varietas yang off type. Simulasi ini juga telah dapat membuktikan bahwa TG UPOV dapat digunakan sebagai panduan pengujian BUSS di Indonesia dan dapat mengidentifikasi varietas contoh untuk panduan pengamatan selanjutnya.

\section{DAFTAR PUSTAKA}

[Deptan] Departemen Pertanian. 2006. Panduan Umum Pengujian Kebaruan, Keunikan, Keseragaman dan Kestabilan. Jakarta: Pusat Perlindungan Varietas Tanaman, Departemen Pertanian (ID).

Gazaro, W.R. 2006. Plant Variety Protection: wich system of protection in the member states of OAPI. World Patent Information 28: 127-131.

[INIBAP] International Network for the Improvement of Banana and Plantain, IPGRI. 2002. Networking Banana and Plantain: INIBAP Annual Report 2001. International Network for the Improvement of Banana and Plantain. Montpeller, France.

Kusumawati, A., Syukriani L. 2008. Identifikasi dan karakterisasi morfologi genotipe pisang (Musa paradisiaca. L) di Kabupaten Agam Provinsi Sumatera Barat. Jerami 1(2): 62-70.

Lalitha, N. 2004. Diffusion of biotechnology and intellectual property rights: emerging issues in India. Ecological Economics 49: 187-198.

Lengkong, E. 2008.Keragaman genetika plasma nutfah pisang (Musa sp.) di Kabupaten Minahasa Selatan dan Minahasa Tenggara.FORMAS 4(1): 302-310.

Megia, R., Hadisunarno, Sulistyaningsih Y.C., Djuita N.R. 2001. Izoyme polymorphisms for cultivar identification in Indonesia banana. Hayati 8(3): 81-85.

Megia, R. 2005. Musa sebagai model genom [ulasan]. Hayati 12(4): 167-170.

Santos, F.S., Moraes Aviani D.D., Hidalgo J.A.F., Machado R.Z., Araújo S.P. 2012. Evolution, importance and evaluation of cultivar protection in Brazil: the work of the SNPC. Crop Breeding and Applied Biotechnology S2: 99-110.

Simmods, N.W., Shepherd K. 1955. The taxonomy and origins of the cultivated bananas.J. Linn Soc Lond Bot. 55 :302312.

Singh, H. 2007. Plant Variety Protection and Food Security: Lessons for Developing Country. JIPR. 12(4): 391-399.

Suhartanto, M.R., Sobir, Harti H., Nasution M.A. 2009. Pengembangan pisang sebagai penopang ketahanan pangan nasional. Prosiding hasil-hasil seminar IPB.

Syukur, M/, Sujiprihati S., Yunianti R. 2012. Teknik Pemuliaan Tanaman. Jakarta (ID): Penebar Swadaya.

[UPOV] Union for the Protection of New Varieties of Plant. 2010. Banana UPOV codes Musa A_Acu; Musaa_Par. Musa Acuminata colla; Musa x paradisiaca L. Guidelines for the conduct of tests for Distinctness, Uniformity and Stability. International Union For The Protection of New Varieties of Plants.

Wirnas, D., Sobir, Surahman M. 2005. Pengembangan kriteria seleksi pada pisang (Musa sp.) berdasarkan analisis lintas. Bul. Agron. 33(3): 48-54. 